\title{
Conjoined Twins: A Report of 3 Cases to Emphasize Prenatal Diagnosis and Challenges
}

\author{
Kiran Agarwal', Lata Agarwal ${ }^{2}, \mathrm{~V} \mathrm{~K} \mathrm{Agrawal}{ }^{3}$, Ashok Agarwal ${ }^{4}$ \\ Dept of Obs/Gyn 1,2, Community Medicine ${ }^{3}$ and Pediatrics ${ }^{4}$, \\ Rohilkhand Medical College Bareilly, UP, Pin 243006.
}

\begin{abstract}
Meeting challenges regarding conjoined twinning and its Prenatal Diagnosis is depicted by three pairs of conjoint twins (all female) diagnosed by ultrasound. All the pairs belonged to Hindu family and there was no history of consanguineous marriage, previous twins in family, ingestion of drugs or exposure to X-ray. First pair of thoracopagus twins was diagnosed at 28 weeks gestation born to twenty two years old primigravida. Second pair of twin was Cephalo-thoracopagus born to twenty seven years old second gravida with a history of one incomplete abortion (two years back). Third pair of twin was craniopagus thoraco-ompalopagus born to twenty five years old second-gravida and parity one at fifteen weeks of gestation.

Incidences of female conjoint twins are more common. Management of conjoint twin still remains a challenge to modern sciences due to multiple congenital anomalies although early and easy diagnosis of conjoint twin is possible because of the availability of ultrasonography.
\end{abstract}

Keywords: Conjoined twins, prenatal diagnosis and challenges

\section{Introduction}

Conjoined twinning is one of the rarest congenital anomalies, and is one of the greatest challenges in modern pediatric surgery ${ }^{1}$. Conjoined twins occur in approximately $0.2: 10,000$ pregnancies, but only $0.05: 10,000$ live births; there is a greater incidence $(70 \%)$ of female conjoined twins ${ }^{2-4}$, but the reason is unknown. Neither conjoined triplets nor recurrence of conjoined twins has been described ${ }^{5,6}$. There is no mention in the literature of conjoined twins born to conjoined-twin parents. Aristotle (384-322 B.C.) wrote about conjoined twins in his memoirs ${ }^{7}$. The term "Janiceps," indicating a form of conjoined twins, comes from the name Janus, a Roman god with two faces (Roman era, approximately $170 \mathrm{AD})^{2}$. Conjoined twins called the "Biddenden Twins" survived for 30 years in Kent, England, around 1100 AD. Antoine Paré, in the 17th century, gives an account of craniopagus twins who lived until 10 years of age. Overall, approximately 500 cases of conjoined twins are reported in the literature ${ }^{3,4}$. A system of classification for conjoined twins, established by St-Hilaire in 1832 is used today ${ }^{8}$. The most famous pair of conjoined twins was Chang and Eng Bunker (1811-1874), Thai brothers born in Siam, now Thailand. They traveled with P.T. Barnum's circus for many years and were billed as the Siamese Twins. Chang and Eng were joined by a band of flesh, cartilage, and their fused livers at the torso. Due to the brothers' fame and the rarity of the condition, the term came to be used as a synonym for conjoined twins.

\section{Cases}

\section{Case 1 (Thoracopagus with Gastrochiasis)}

A pair of thoracopagus twins was diagnosed antenatally at 28 weeks gestation by fetal ultrasound. A twenty two years old pimigravida, Hindu by religion with history of 27 weeks of gestation reported with complaint of premature labour pain. There was no history of

Correspondence

Dr V. K. Agrawal, MD, DIH, DHA, DIT, FIPHA

Prof \& HOD, Dept of Community Medicine,

Rohilkhand Medical College \& Hospital, Bareilly (UP) Pin 243006

Phone: 09368394443

E-mail : vijenderagrawal@yahoo.co.in 


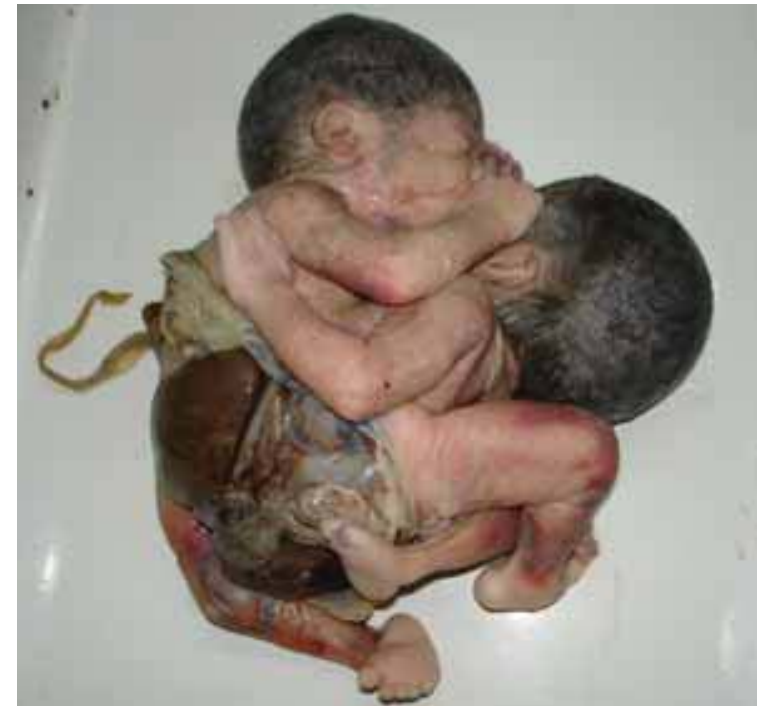

Fig 1. Conjoined twins

(thoracopagus with astrochiasis)

consanguineous marriage. The period of gestation was uneventful. There was no history of previous antenatal checkup or any investigation. She had no history of previous twin in her family. There was no history of ingestion of drugs or exposure to X-ray. Her Blood group was O positive. Ultrasound examination revealed two live fetuses. Fetal movements and cardiac activity was well visualized. Heart rates of fetuses were in range of 142-148/minute. Liquor was adequate and clear. Placenta was fundal and not low lying. Average age of fetus was calculated was found 27 week and zero days by biparietal distance (BPD). Estimated fetal weight was in range of 593 to 689 gram. Abdominal organs were floating in amniotic fluid. Both fetuses were joined in midline. Distal limbs were short. The couple was then informed of the ultrasound findings and counseled on the various management options. Since premature labour pains have already started and both fetuses were having serious congenital abnormalities vaginal delivery was planned. Cerviprime gel was used for cervical ripening and subsequently tab misoprostol was used by vaginal route. Vitals parameters were monitored during intra-natal period and were within normal range. It was breech delivery and both fetuses were stillborns. Both fetus were female and joined at midline (Fig 1). Gastroschisis were present in both fetuses. Evisceration of intestinal loops as well as Liver was present and there was no surrounding membrane unlike in omphalocoele. Postnatal period was uneventful and mother was discharged after $24 \mathrm{Hrs}$.

\section{Case 2 (Cephalothoracopagus)}

A twenty seven years old second gravida (Hindu by religion) with a history of one incomplete abortion (two years back) presented with 9 weeks 3 days of

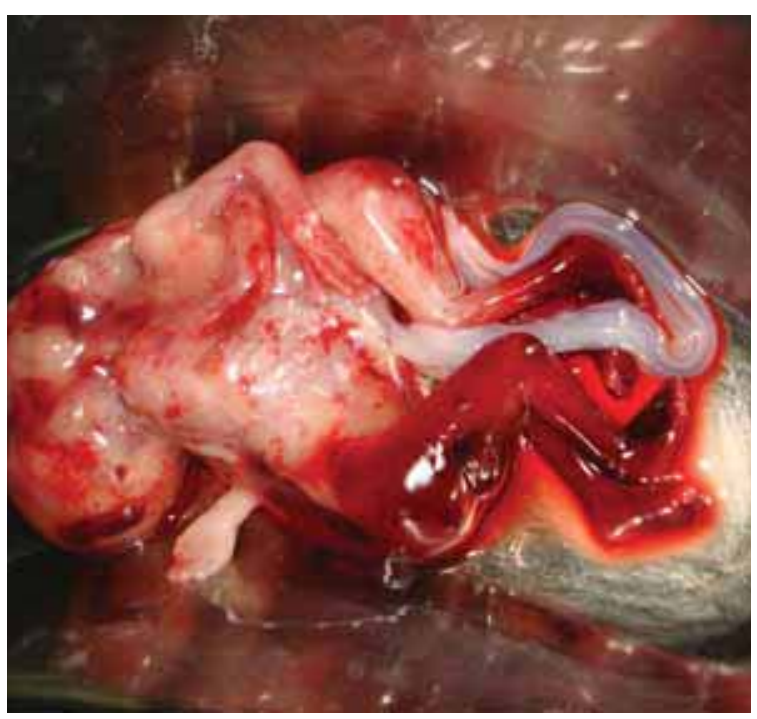

Fig 2. Conjoined twins (Cephalothoracopagus)

gestation. She reported with complaint of spotting. Her blood group was B positive. Ultrasound was done but it was inconclusive. She had no history of previous twin or twin in her family. There was no history of ingestion of drug. She reported again at 13 weeks of gestation. At this time ultrasound examination revealed two fetuses. Placenta was fundal and not low lying. Average age of fetus was calculated and found 13 week and 2 days by biparietal distance (BPD). Both fetuses were joined in midline. Diagnosis of Cephalo-thoracopagus was given since head, thorax and abdomen fused in midline. Cephalo-thoracopagus is a combination of cephalopagus and thoracopagus (twins with conjoined heads, necks and chests, with separate arms and legs). These usually share a heart as well as a brain and are also non-viable. The couple was then informed of the ultrasound findings and counseled on the various management options. In view of serious congenital anomalies couple insisted for MTP. Tab misoprostol was used by vaginal route for MTP. Both fetuses were female and were stillborn (Fig 2). There was no complication or side effects and mother was discharged after 24 Hrs.

\section{Case 3 (Craniopagus Thoraco-Ompalopagus)}

A twenty five years old second-gravida and parity one (Hindu by religion) reported with 15 weeks of gestation. The period of gestation was uneventful. She had no history of previous twin or twin in her family. There was no history of ingestion of drug. Ultrasound examination revealed two live fetuses. Fetal movements and cardiac activity was well visualized. Liquor was adequate and clear. Both placentas were fundal posterior and not low lying. Average age of fetus was calculated was found 15 week and three days Skull vault of both fetuses were 
fused in midline. Thorax and abdominal walls were also fused. Umbilical vein was single. Fetal spine was normal in both fetuses. Mild fetus ascites were seen. All four limbs were separated in both fetuses. The couple was then informed of the ultrasound findings and counseled on the various management options. In view of serious congenital anomalies couple insisted for MTP. Tab misoprostol was used by vaginal route for MTP. Fetuses were aborted in pieces were stillborn. There was no complication and side effects. Mother was discharged after $24 \mathrm{Hrs}$.

\section{Comment}

We present three cases of conjoint twins delivered during the prospective study period carried out in a tertiary care teaching hospital from May 09 to May 10. Diagnosis of conjoint twin was confirmed by ultrasound examination. Detailed history regarding various risk factors of twin pregnancy was recorded in confirmed cases of conjoint twin on a questionnaire. The couple was then informed of the ultrasound findings and counseled on the various management options and MTP / delivery was planned accordingly. Conjoint twins was examined for various congenital anomalies and classified according to approved nomenclature discussing the challenges of prenatal diagnosis, a brief literature review and a mention of other relevant imaging modalities

Monoamniotic twin pregnancies comprise 1\% of monozygotic twin pregnancies (approximately $1: 25,000$ pregnancies $)^{9}$. Placentation in twin pregnancies depends on the stage of embryonic division; if cell differentiation takes place after the 14th day of embryonic development, it is incomplete, resulting in conjoined twins ${ }^{3}$. The etiology of conjoined twins is not known. In general there are no karyotypic abnormalities, nor does race, heredity, birth order, or consanguinity appear to influence the process $^{8}$. Two prominent theories explain the appearance of conjoined twins, the theory of fusion and the theory of fission. In the fusion theory, authors propose that the twins join secondary to late embryonic division; in the fission theory, some authors' feel there is instead an absence of complete embryonic division.

Conjoined twin classification establishes the function and importance of the site of union, common organs, and their symmetry/asymmetry. Duhamel classification is based on internal anatomic relationships so as to evaluate prognosis ${ }^{3}$. Wilder classes conjoined twins by external attachment, permitting distinction of autosite (independent) twins from parabiotic twins (one normal and one parabiotic, e.g. fetus in fetu, usually discovered at birth) ${ }^{10}$. Pathogenesis of this entity is obscure. It seems to originate from a heteropagus twin inside the second twin, probably the result of a monochorionic diamniotic twin pregnancy with anastomosis of vitelline circulation.

The prognosis for conjoined twins is generally unfavorable, with approximately $40 \%$ of cases stillborn ${ }^{6}$. The worst prognoses concern craniopagus twins and those with a sole cardiac mass. Structural anomalies are frequently found such as polyhydramnios $(50 \%)$, cardiac malformations, neural tube defects common omphaloceles and gastroschisis which represents herniation of abdominal contents through a paramedian full-thickness abdominal fusion defect without involving the umbilical cord.

Upon discovery of nonviable conjoined twins, interruption of pregnancy should therefore be recommended. In the case of potentially viable conjoined twins, after 24 weeks GA the choice between vaginal delivery or prophylactic caesarian section should be made based on maternal safety and neonatal criteria. Caesarian section avoids dystocia, uterine rupture, and fetal death in utero. Approximately six to ten cases of conjoined twins per annum worldwide are treated surgically. The surgery is most successful when commonality of fetal organs is limited; surgical intervention often takes place around one year of age.

Only four cases of conjoined twins were seen before birth radiographically, prior to the early sonographic era of the 1960s. In 1967, Rudolph ${ }^{6}$ reported prenatal radiographic discovery of 16 out of 65 cases of conjoined twins by radiography. In 1976, Wilson ${ }^{11}$ made a radiographic discovery at 35 weeks of conjoined twins at 35 weeks. In 1989, Grutter $^{5}$ observed thoracopagus twins at 16 weeks. Sonography has demonstrated conjoined twins at the end of the first trimester since $1995^{7}$. Yin recently diagnosed conjoined twins by embryoscopy. Maymon reported $3 \mathrm{D}$ sonographic analysis of conjoined twins at 10 weeks GA; he prefers 2D to 3D sonography for diagnosis $^{12}$. Fast MRI is becoming an important tool for prognostic assessment, in the first trimester for anatomic evaluation, and later in pregnancy to plan the route of delivery and separation surgery when possible.

\section{References}

1. Ryan M, McAdams, Kirk A, Milhoan Brian H, Hall Randy G. Richardson Prenatal and postnatal imaging of thoracopagus conjoined twins with a shared six-chamber heart Pediatr Radiol 2004:34: 816-819.

2. Wilson RL, Cetrulo CL, Shaub MS. The prepartum diagnosis of conjoined twins by the use of diagnosis ultrasound. Am J Obstet Gynecol 1976; 126: 737 . 
3. Broussin B, Carles D. Les jumeaux conjoints : Diagnostic anténatal. Med Foet Echo Gyn, 1999, 37, 4-9.

4. Barth RA, Filly RA, Goldberg JD, Moore P, Silverman NH. Conjoined twins: Prenatal diagnosis and assessment of associated malformations. Radiology 1990; 177: 201-7.

5. Moussaoui RD. Jumeaux conjoints: A propos d'une observation. Gynécologie Internationale 1997, 6: 59-61.

6. Puech F, Vaast P, Codaccioni X, Hubert D. Grossesses gémellaires et multiples. Etude anatomo-clinique et prise en charge. Editions techniques- Encycl Med Chir (Paris-France). Obstetrique, 5-030-A-10, 1993, 16.

7. Barhmi R, Ferhati D, Melhouf MA, Nabil S, El Hamany Z, Kharbach A, Chaoui A. Jumeaux conjoints : Diagnostic échographique à 22 semaines. A propos d'un cas. Rev Fr Gynécol Obstet 1996; 91: 547-50.
8. Vaughn TC, Powell LC. The obstetrical management of conjoined twins. Obstet Gynecol 1979; 53: 67S-72S.

9. Maggio M, Callan NA, Kamal A, Sanders RC. The first trimester ultrasonographic diagnosis of conjoined twins. Am J Obstet Gynecol 1985; 152: 833-5.

10. Maggio M, Callan NA, Kamal A, Sanders RC. The first trimester ultrasonographic diagnosis of conjoined twins. Am J Obstet Gynecol 1985; 152: 833-5.

11. Tongsong T, Chanprapaph P, Pongsatha S. Firsttrimester diagnosis of conjoined twins: a report of three cases. Ultrasound Obstet Gynecol 1999; 14: 434-7.

12 Chen CP, Lee CC, Liu FF, Jan SW, Lin MH, Chen BF. Prenatal diagnosis of cephalothoracopagus janiceps monosymmetros. Prenat Diagn 1997; 17: 384-8. 